\title{
【Transaction】
}

\section{Preparation of Ultrahigh-Molecular-Weight Polyethylene Tapes by Multiple Melt Processing}

\author{
Masaki Kakiage*1,2,\# and Kenta Komatsu*3 \\ ${ }^{* 1}$ Institute for Fiber Engineering, Shinshu University (IFES), Interdisciplinary Cluster for Cutting Edge Research (ICCER), \\ Shinshu University, 3-15-1 Tokida, Ueda, Nagano 386-8567, Japan \\ ${ }^{* 2}$ Division of Molecular Science, Graduate School of Science and Technology, Gunma University, 1-5-1 Tenjin-cho, Kiryu, \\ Gunma 376-8515, Japan \\ ${ }^{* 3}$ Department of Textile Science and Technology, Graduate School of Science and Technology, Shinshu University, 3-15-1 Tokida, \\ Ueda, Nagano 386-8567, Japan
}

\begin{abstract}
Ultrahigh-molecular-weight polyethylene (UHMW-PE) tapes are commercially prepared by skiving a compacted block of UHMW-PE powder. However, the mechanical properties of a skived film are poor, and the production of a thin film is difficult. In this study, we succeeded in preparing UHMW-PE tapes from UHMW$\mathrm{PE}$ reactor powder by multiple melt processing, i.e., melt-extrusion, melt-rolling, and melt-drawing. UHMW-PE reactor powder was continuously melt-extruded into a strand without melt fracture. The obtained meltextruded strand was repeatedly melt-rolled at 155 and $150{ }^{\circ} \mathrm{C}$ in order and with stepwise reduction of the gap between the rolls to form a tape. The obtained tape (as-rolled tape) was melt-drawn at $155{ }^{\circ} \mathrm{C}$ to achieve high tensile strength and thin thickness. The maximum draw ratio $(D R)$ was the highest under a strain rate of $5 /$ min. The development of the crystalline structure of the melt-drawn tapes was investigated by wide-angle $\mathrm{X}$ -ray diffraction measurements and differential scanning calorimetry measurements. Extended-chain crystals (ECCs) were formed by melt-drawing of the as-rolled tape and developed with increasing $D R$, resulting in high tensile strength. The melt-drawn tape prepared by melt-drawing with $D R$ of 15 under a strain rate of $5 / \mathrm{min}$ exhibited the most enhanced ECC formation and the highest degree of crystalline orientation, resulting in a tensile strength of $0.56 \mathrm{GPa}$ and a thickness of $70 \mu \mathrm{m}$. Consequently, a thin UHMW-PE tape with superior tensile strength was prepared from UHMW-PE reactor powder by multiple melt processing.
\end{abstract}

(Received 21 August, 2020; Accepted 3 November, 2020)

\section{Introduction}

Ultrahigh-molecular-weight polyethylene (UHMWPE) with an MW of over $10^{6}$ is an important highperformance polymer material. UHMW-PE tapes are widely used owing to their abrasion resistance and low coefficient of friction. The melt-extrusion of UHMW-PE is difficult owing to the high melt viscosity. The high melt viscosity of molten UHMW-PE induces melt fracture on the surface of extrudates. Hence, UHMW-PE films (tapes) are commercially prepared by skiving a compacted block of UHMW-PE powder. However, the mechanical properties of a skived film are poor (e.g., tensile strength of approximately $\sim 0.1$ GPa [1]) owing to the boundary separation between powder particles, and the production of a film with thickness below $100 \mu \mathrm{m}$ is difficult [2]. Gel-spinning is a well-known method for obtaining high-performance UHMW-PE fibers [3-5]. Unfortunately, however, the gel-spinning process requires a large amount of organic solvent.

A UHMW polymer can be drawn even from the molten state owing to its high melt viscosity [1, 2, 623]. The high melt viscosity means a longer relaxation time [24]; thus, the chain orientation will be retained during drawing from the melt. Molten UHMW polymer exhibits elastic deformability, which is homogeneously transmitted within the entire sample through chain entanglements, resulting in oriented crystallization. The formation of extended-chain crystals (ECCs) by oriented crystallization during melt-drawing results in a high tensile strength [8-10,

\# corresponding author: Masaki Kakiage (E-mail: kakiage@gunma-u.ac.jp) 
23]. Consequently, the melt-drawing technique produces a high-performance UHMW-PE material without the use of a solvent [1, 2, 19, 23]. Recently, we have successfully prepared high-performance UHMW-PE fibers by melt-processing, i.e., a combination of melt-spinning and melt-drawing [23]. An as-spun UHMW-PE fiber without melt fracture was continuously obtained by melt-spinning from UHMW-PE reactor powder. The obtained as-spun fiber was melt-drawn to achieve oriented crystallization and reduce the fiber diameter, resulting in ECC formation and high tensile strength.

In this study, we attempt to prepare thin UHMWPE tapes with high tensile strength from UHMW-PE reactor powder by multiple melt processing, i.e., meltextrusion, melt-rolling, and melt-drawing. UHMW-PE reactor powder was melt-extruded into a strand without melt fracture based on our method [23]. Meltrolling [1, 25] of a melt-extruded strand was performed to form a tape. Calendar rolling allows continuous film (tape) manufacturing [1, 25-29]. We reported calendar rolling from UHMW-PE reactor powder above melting temperature for preparing a film, since the high melt viscosity of molten UHMW$\mathrm{PE}$ enables the melt-rolling [1]. The combination of melt-extrusion and melt-rolling is expected to form a tape with sufficient powder adhesion. Moreover, meltdrawing of the melt-rolled tape was performed to achieve high tensile strength and thin thickness. This approach of multiple melt processing, i.e., meltextrusion, melt-rolling, and melt-drawing, is a promising methodology for nonsolvent green processing for preparing high-performance thin UHMW-PE tapes.

\section{Experimental Section}

\subsection{Materials}

UHMW-PE reactor powder having a viscosityaverage MW of $5.90 \times 10^{6}$ (HI-ZEX MILLION $630 \mathrm{M}$, Mitsui Chemicals, Inc., Japan) was used. Before meltextrusion, the UHMW-PE powder was mixed with an acetone solution of two antioxidants, $0.5 \mathrm{wt} \%$ (based on polymer) of both octadecyl 3-(3,5-di-tert-butyl-4hydroxyphenyl)propionate (ADK STAB AO-50, ADEKA Corporation, Japan) and 2,2'-methylenebis (4,6-di-tert-butylphenyl) 2-ethylhexyl phosphite (ADK STAB HP-10, ADEKA Corporation, Japan), and dried at room temperature.

\subsection{Melt-extrusion}

Melt-extrusion of UHMW-PE reactor powder was conducted using a DSM Xplore MC 15 twin-screw microcompounder equipped with a $1.5 \mathrm{~mm}$-diameter nozzle. The barrel temperature, nozzle temperature, and screw speed were $180{ }^{\circ} \mathrm{C}, 160{ }^{\circ} \mathrm{C}$, and $5 \mathrm{rpm}$, respectively. The UHMW-PE powder was continuously supplied to the barrel of the microcompounder and extruded under a constant force of approximately $4 \times 10^{3} \mathrm{~N}$. The extruded sample was pulled out at a load of $0.5 \mathrm{~N}$, and a strand was obtained.

\subsection{Melt-rolling}

The tape was formed using a roll-processing machine with a parallel arrangement of two stainlesssteel rolls with $40 \mathrm{~mm}$ diameter and $132 \mathrm{~mm}$ width (IMC-110 F-B, Imoto machinery Co., Ltd.). The obtained melt-extruded strand was repeatedly meltrolled at $155{ }^{\circ} \mathrm{C}$ with stepwise decreasing gaps between the two rolls of $1.0,0.5,0.4$, and $0.3 \mathrm{~mm}$, and then at $150{ }^{\circ} \mathrm{C}$ with stepwise decreasing gaps of $0.2,0.1$ 0.05 , and $0.01 \mathrm{~mm}$. The rolling procedure was performed twice at each gap with different rolling speeds of 0.125 and $0.625 \mathrm{~m} / \mathrm{min}$. The melt-rolled tape was pulled out at a load of $0.2 \mathrm{~N}$, and an as-rolled tape was obtained.

\subsection{Melt-drawing}

The obtained as-rolled tape was cut to $3 \mathrm{~mm}$ width and then melt-drawn at $155{ }^{\circ} \mathrm{C}$ in a silicone oil bath. Before drawing, the sample was held at the drawing temperature for $5 \mathrm{~min}$ for temperature equilibration. The strain rates of drawing were 1,5 , and $10 / \mathrm{min}$.

\subsection{Measurements}

A Rigaku Thermo Plus DSC 8230 was used for differential scanning calorimetry (DSC) measurements. Heating scans were performed up to $180{ }^{\circ} \mathrm{C}$ at a rate of $5{ }^{\circ} \mathrm{C} / \mathrm{min}$ under a nitrogen gas flow $(50 \mathrm{~mL} / \mathrm{min})$. Wide-angle X-ray diffraction (WAXD) measurements were performed using an X-ray generator (Rigaku RA-Micro 7) equipped with an imaging plate (Rigaku R-AXIS $\mathrm{IV}^{++}$). The X-ray source was the $\mathrm{CuK} \alpha$ radiation $(0.15418 \mathrm{~nm})$ generated at $40 \mathrm{kV}$ and $20 \mathrm{~mA}$. The exposure time was set to $1 \mathrm{~min}$ and the camera distance was fixed at $150 \mathrm{~mm}$. Optical microscopy observations were conducted using a KEYENCE VHX-2000 digital microscope with a VH-Z100UR lens. Tensile testing was conducted using a tensile tester (TENSILON RTC-1250A, A\&D Co., Ltd.). The gauge length and tensile speed were set to $10 \mathrm{~mm}$ and 
$10 \mathrm{~mm} / \mathrm{min}$, respectively.

\subsection{Analysis}

The crystalline orientation was evaluated from the azimuthal profile extracted along the azimuthal direction at the orthorhombic (110) reflection at $2 \theta=$ $21.0-22.4^{\circ}$ of the WAXD pattern. The degree of crystalline orientation $\left(D_{\mathrm{c}}\right)$ for the melt-drawn tapes was evaluated using the following equation,

$$
D_{\mathrm{c}}(\%)=\frac{180-\mathrm{FWHM}(\text { deg. })}{180} \times 100
$$

where FWHM is the full width at half maximum of the maximum peak at azimuthal angle of $90^{\circ}$ in the azimuthal profile. The value of the FWHM of the maximum peak was determined by the peak fitting using the pseudo-Voigt function.

\section{Results and discussion}

We recently reported that a suitable combination of barrel temperature and nozzle temperature enables the continuous preparation of a melt-extruded UHMW-PE sample without melt fracture from reactor powder [23]. A homogeneous melt-extruded strand without melt fracture was continuously obtained based on our method. Fig. 1 shows an optical microscopic image of the melt-extruded strand prepared at the barrel temperature and nozzle temperature of $180{ }^{\circ} \mathrm{C}$ and $160{ }^{\circ} \mathrm{C}$, respectively. The diameter of the obtained melt-extruded strand was approximately $1.7 \mathrm{~mm}$.

The obtained melt-extruded strand was meltrolled repeatedly above the sample melting temperature $\left(133.1^{\circ} \mathrm{C}\right)$ to form a tape. Melt-rolling of the strand was performed at temperatures of 155 and $150{ }^{\circ} \mathrm{C}$ in order and with stepwise reduction of the gap between the rolls to avoid breaking the sample. The

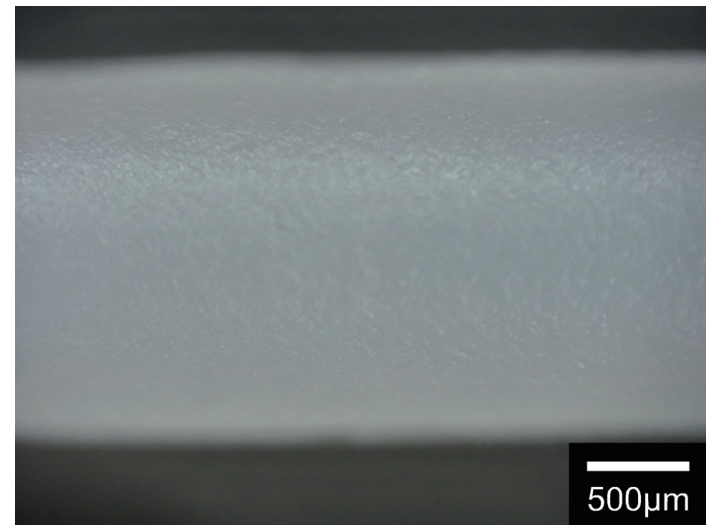

Fig. 1 Optical microscopic image of melt-extruded strand. strand was melt-broken when rolling was performed at $160{ }^{\circ} \mathrm{C}$, and the compression was difficult when rolling was performed at $140{ }^{\circ} \mathrm{C}$. On the other hand, rolling at $155{ }^{\circ} \mathrm{C}$ was effective for forming the tape, but melt-breaking occurred at the gap of $0.2 \mathrm{~mm}$. Thus, the rolling temperature was first set at $155{ }^{\circ} \mathrm{C}$ with decreasing the gap stepwise from 1.0 to $0.3 \mathrm{~mm}$ and then at $150{ }^{\circ} \mathrm{C}$ with decreasing the gap stepwise from 0.2 to $0.01 \mathrm{~mm}$. Fig. 2(a) shows an optical microscopic image of the obtained melt-rolled tape. A homogeneous structure without a powder boundary was observed; thus, an as-rolled tape was obtained by this process. The thickness of the obtained as-rolled tape was approximately $200 \mu \mathrm{m}$. Note that a boundary attributed to the powder particles (particle size of approximately $150 \mu \mathrm{m}$ ) was clearly observed for a melt-rolled sample directly rolled from UHMW$\mathrm{PE}$ reactor powder [Fig. 2(b)], indicating poor adhesion between the powder particles. It is known that the adhesion between the powder particles is a key to effective chain orientation during later tensile drawing $[1,28,30]$ because the sample is easily broken in early stages of drawing when the adhesion is not strong enough to transmit the tensile force. Therefore the combination of melt-extrusion and melt-rolling is effective for the preparation of UHMW-PE tape
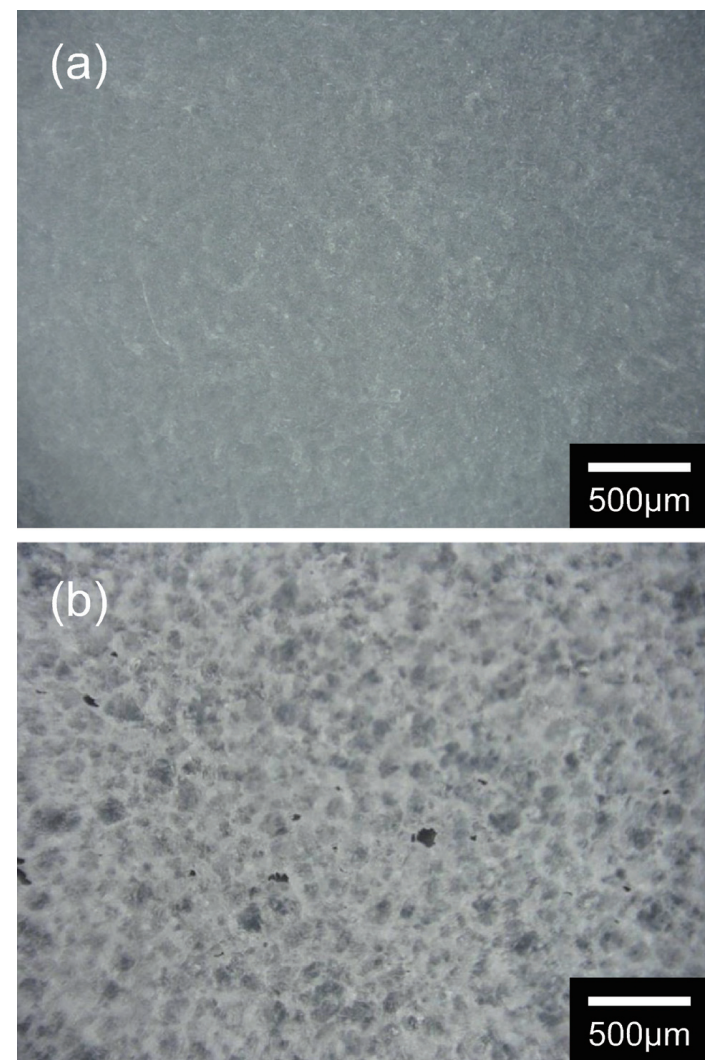

Fig. 2 Optical microscopic image of (a) as-rolled tape. For comparison, a melt-rolled sample directly rolled from reactor powder is also shown in (b). 
without a boundary between powder particles.

The WAXD patterns and the azimuthal profiles extracted along the azimuthal direction at the orthorhombic (110) reflection for the melt-extruded strand and as-rolled tape are shown in Figs. 3 and 4, respectively. Slight chain orientation toward the rolling direction was observed for the as-rolled tape. Fig. 5 shows the DSC heating thermograms for the melt-extruded strand and as-rolled tape. A melting endotherm at $131-133{ }^{\circ} \mathrm{C}$ was observed for both samples, indicating that the melt-extruded strand and as-rolled tape consist of mainly folded-chain crystals (FCCs) formed during cooling after melt processing. Furthermore, a small higher endotherm at approximately $152{ }^{\circ} \mathrm{C}$ was observed for the as-rolled tape, similar to that attributed to ECCs formed by oriented crystallization during melt-drawing [6-9, 16, 21, 23]. The results of the WAXD and DSC measurements indicate that shear stress can induce chain orientation even for rolling in the molten state and the formation of a small amount of ECC by the melt-rolling.

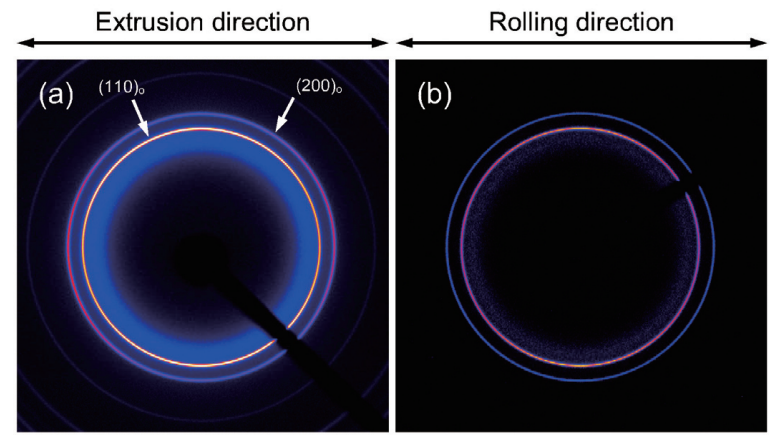

Fig. 3 WAXD patterns of (a) melt-extruded strand and (b) as-rolled tape.

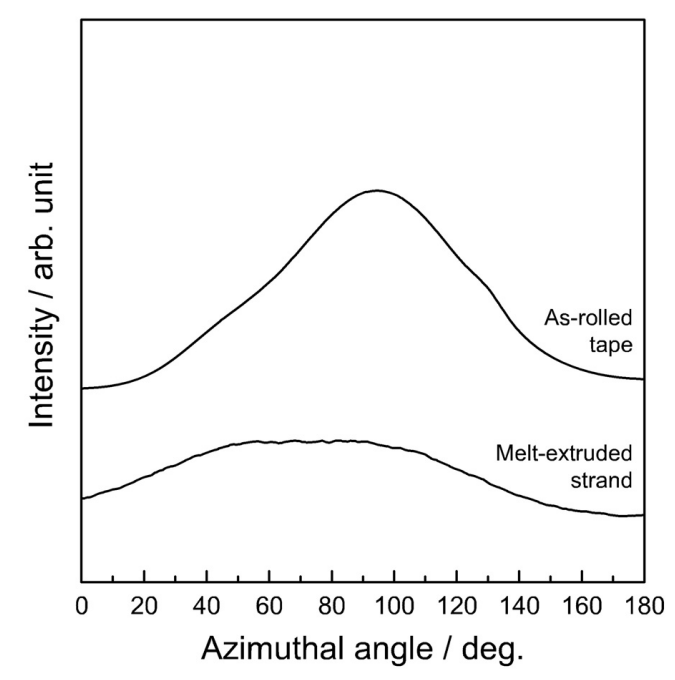

Fig. 4 Azimuthal profiles extracted along azimuthal direction at (110) reflection of WAXD patterns for melt-extruded strand and as-rolled tape.

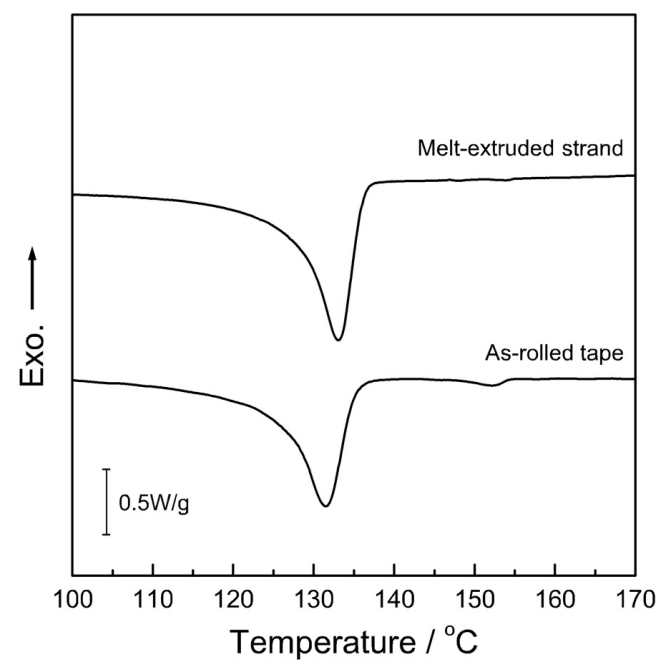

Fig. 5 DSC heating thermograms for melt-extruded strand and as-rolled tape.

The as-rolled tape was melt-drawn at $155^{\circ} \mathrm{C}[10]$, considerably above the melting temperature of the asrolled tape $\left(131.5^{\circ} \mathrm{C}\right.$, Fig. 5). The effect of the strain rate for melt-drawing on the formation of ECCs and the drawability was investigated. Fig. 6 shows the DSC heating thermograms for melt-drawn tapes with a constant draw ratio $(D R)$ of 10 under strain rates of 1 , 5, and 10/min. Lower and higher endotherms at approximately $132{ }^{\circ} \mathrm{C}$ and above $140{ }^{\circ} \mathrm{C}$, respectively, were observed for the melt-drawn tapes. Previous reports on the melt-drawing of UHMW-PE [6-9, 16, 21, 23] revealed that the lower endotherm is due to the melting of FCCs and the higher endotherm is due to the melting of ECCs and the orthorhombic-hexagonal phase transition/melting of the hexagonal phase attributed to ECCs [16, 18, 31, 32]. UHMW-PE has a much higher MW (over $10^{6}$ ) than an entanglement

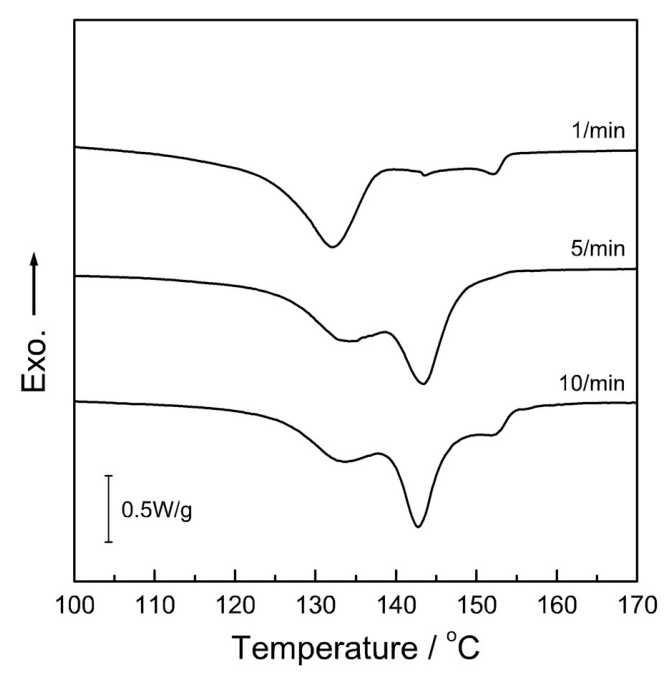

Fig. 6 DSC heating thermograms for melt-drawn tapes with a constant $D R$ of 10 under strain rates of 1,5 , and $10 / \mathrm{min}$. 

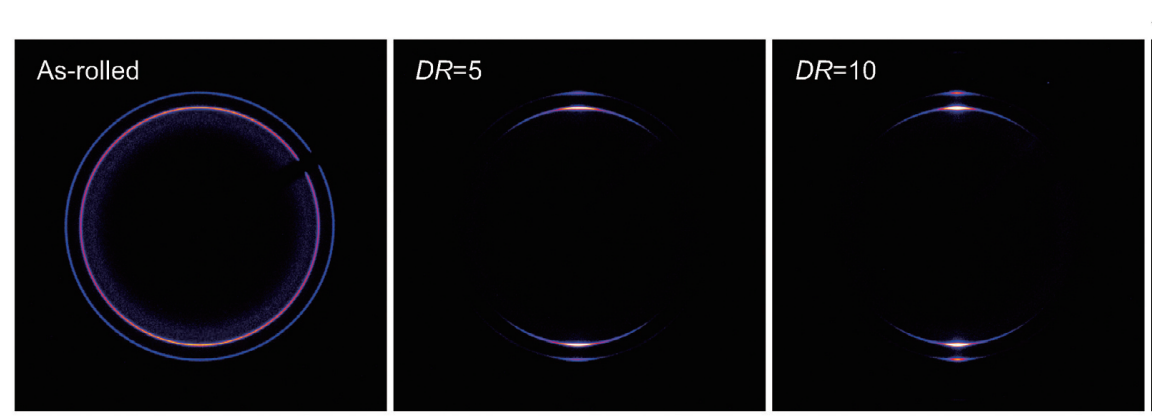

Drawing direction

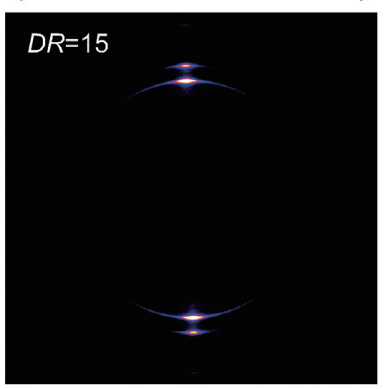

Fig. 7 WAXD patterns of as-rolled tape and melt-drawn tapes with different $D R$ under strain rate of $5 / \mathrm{min}$.

MW of PE $\left(1.39 \times 10^{3}\right)$ [33]. Molten UHMW-PE contains many entanglements including deep (tight) entanglements due to its long chain length, whereas deep (tight) entanglements are not recognized for molten normal MW PE [17]. During the drawing of molten UHMW-PE, deep (tight) entanglements effectively transmit the applied stress, resulting in the disentanglement of amorphous chains with shallow (loose) entanglements [17] and the formation of ECCs by oriented crystallization of disentangled chains between deep (tight) entanglements [7, 21]. The higher endotherm became predominant with increasing strain rate. This indicates the development of ECCs with increasing strain rate owing to the increase in the applied stress. In contrast, the higher endotherm was unclear at $1 / \mathrm{min}$. Excessive disentanglement by chain relaxation occurs for meltdrawing at a lower strain rate [7, 10], resulting in lower applied stress and less ECC development. ECCs effectively formed at the highest strain rate of $10 / \mathrm{min}$. However, the disentanglement of chains during meltdrawing was restricted [7, 10], similarly to meltdrawing at a lower temperature in accordance with the temperature-strain rate relationship for meltdrawing $[12,23]$, decreasing the maximum $D R$. The maximum $D R$ s at strain rates of 1,5 , and $10 /$ min were 11,18 , and 13, respectively. Melt-drawing at a strain rate of $5 / \mathrm{min}$ promotes the well-balanced development of chain disentanglement and oriented crystallization, resulting in the formation of ECCs and superior drawability.

The chain orientation and the development of ECCs by melt-drawing were investigated by WAXD and DSC measurements. Fig. 7 shows the WAXD patterns of the as-rolled tape and the melt-drawn tapes with different $D R$ under a strain rate of $5 / \mathrm{min}$. The orthorhombic (110) reflection consisting of both spot-shaped and arc-shaped reflections was observed in the direction perpendicular to the drawing direction for the melt-drawn tapes, although only a ring-shaped reflection was observed for the as-rolled tape. This combination of spot- and arc-shaped reflections is typical for a shish-kebab structure consisting of ECCs and FCCs of a melt-drawn UHMW-PE [6-9, 23]. The spot-shaped reflection is attributed to ECCs formed during melt-drawing, and the arc-shaped reflection is attributed to FCCs formed during cooling after melt-drawing. The arc-shaped reflection transformed to the spot-shaped reflection with increasing $D R$, indicating that the ECC formation and the chain orientation toward the drawing direction accelerated with increasing $D R$. The (110) reflection mainly consisting of the spot-shaped reflection was observed for the melt-drawn tapes with $D R$ of 15 . Changes in the crystalline orientation of the melt-drawn tapes were quantitatively analyzed by comparing the azimuthal profiles extracted along the azimuthal direction at the (110) reflection, as shown in Fig. 8. A maximum peak corresponding to the spot-shaped reflection appeared at $90^{\circ}$ for the melt-drawn tapes, although only broad peak corresponding to the arc-shaped reflection was observed for the as-rolled tape, indicating the ECC formation and the chain orientation in the drawing direction by melt-drawing. The maximum peak became predominant and the width decreased with increasing $D R$. $D_{\text {c }}$ for the melt-drawn tape increased with increasing $D R$; $D_{\text {c }}$ evaluated from FWHM of the maximum peak for the melt-drawn tapes with $D R$ of 5 , 10, and 15 was $94.6,96.8$, and $97.6 \%$, respectively. Fig. 9 shows the DSC heating thermograms for the as-rolled tape and the melt-drawn tapes with different $D R$ under a strain rate of $5 / \mathrm{min}$. The higher endotherm became predominant at $D R$ of 10 and 15, indicating enhanced ECC formation. The melt-drawn tape with $D R$ of 15 mainly consists of ECCs. These results indicate that melt-drawing of the as-rolled tape promotes the development of ECCs with a chain orientation. The melt-drawn tape prepared by meltdrawing with $D R$ of 15 under a strain rate of $5 / \mathrm{min}$ 


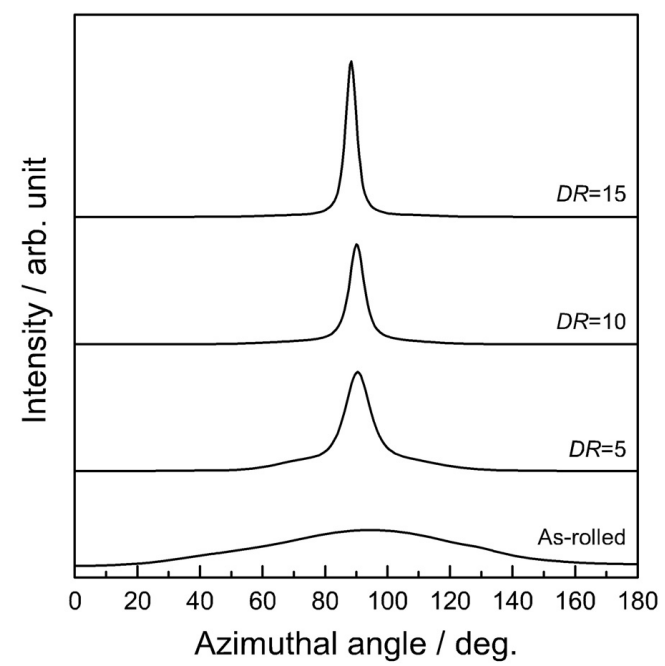

Fig. 8 Azimuthal profiles extracted along azimuthal direction at (110) reflection of WAXD patterns for as-rolled tape and melt-drawn tapes with different $D R$ under strain rate of $5 / \mathrm{min}$.

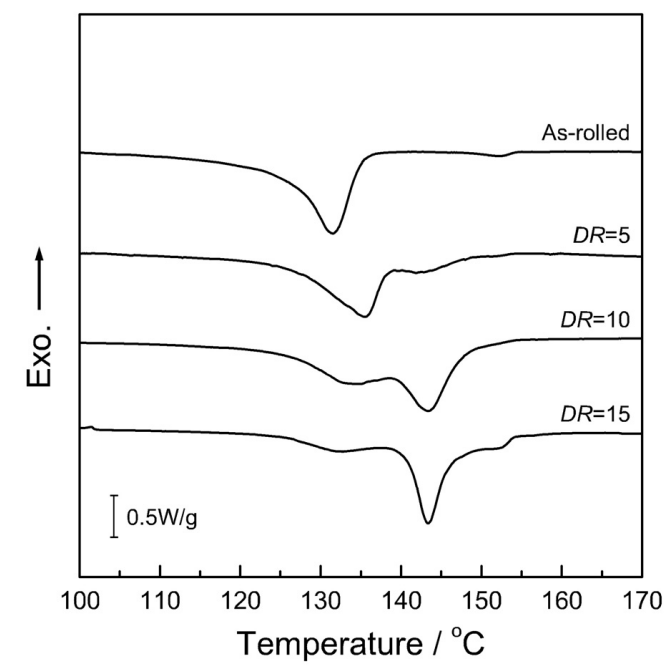

Fig. 9 DSC heating thermograms for as-rolled tape and melt-drawn tapes with different $D R$ under strain rate of $5 / \mathrm{min}$.

exhibited the most enhanced ECC formation and the highest $D_{\mathrm{c}}$.

The development of the crystalline structure improved the mechanical properties of the meltdrawn tapes. Fig. 10 shows the stress-strain curves for the as-rolled tape and the melt-drawn tapes with different $D R$ under a strain rate of $5 / \mathrm{min}$. The tensile strength increased with increasing $D R$, corresponding to the development of ECCs (Fig. 9) with a chain orientation (Figs. 7 and 8). The tensile strength of the melt-drawn samples increased with increasing ECC formation and higher chain orientation [23]. The formation of ECCs was enhanced by melt-drawing at a higher $D R$, resulting in higher tensile strength. The melt-drawn tape prepared by melt-drawing with $D R$

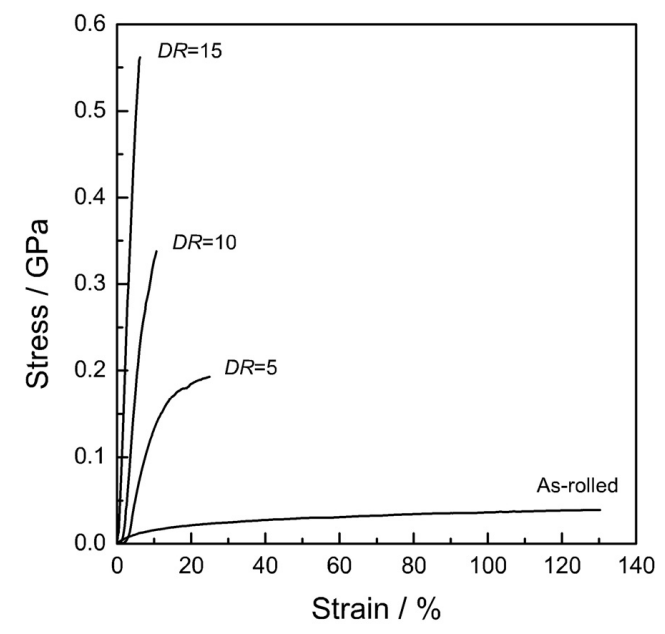

Fig. 10 Stress-strain curves of as-rolled tape and melt-drawn tapes with different $D R$ under strain rate of $5 / \mathrm{min}$.

of 15 under a strain rate of $5 / \mathrm{min}$, which exhibited the most enhanced ECC formation and the highest $D_{\mathrm{c}}$, had the highest tensile strength. The tensile strength, tensile modulus, and thickness of the obtained meltdrawn tape were $0.56 \mathrm{GPa}, 11 \mathrm{GPa}$, and $70 \mu \mathrm{m}$, respectively, which are superior to those of a commercial skived film (tensile strength of $\sim 0.1 \mathrm{GPa}$ and thickness of $100 \sim \mu \mathrm{m})$. Fig. 11 shows optical microscopic images of the melt-drawn tape prepared with $D R$ of 15 under a strain rate of $5 / \mathrm{min}$. The oriented morphology was observed for the obtained melt-drawn tape. Consequently, a thin UHMW-PE tape with superior tensile strength was prepared by

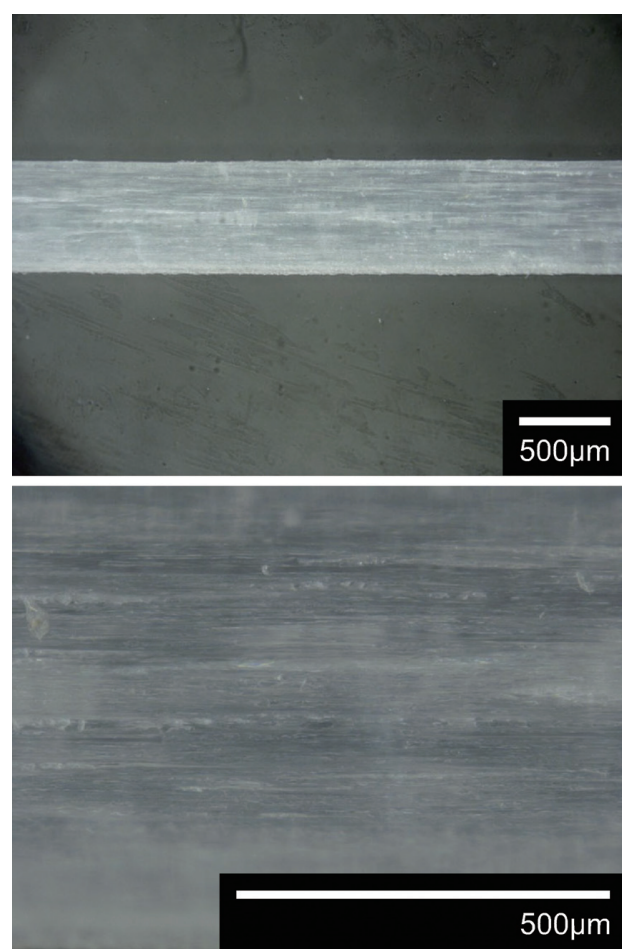

Fig. 11 Optical microscopic images of melt-drawn tape with $D R$ of 15 under strain rate of $5 / \mathrm{min}$. 
multiple melt processing, i.e., melt-extrusion, meltrolling, and melt-drawing. This approach enables continuous processing and is a promising solvent-free green processing methodology for the preparation of high-strength thin UHMW-PE tapes.

\section{Conclusions}

In this study, UHMW-PE tapes were prepared from UHMW-PE reactor powder by multiple melt processing, i.e., melt-extrusion, melt-rolling, and meltdrawing. A UHMW-PE strand without melt fracture was continuously obtained by melt-extrusion of UHMW-PE reactor powder at the barrel temperature and nozzle temperature of $180{ }^{\circ} \mathrm{C}$ and $160{ }^{\circ} \mathrm{C}$, respectively. The diameter of the obtained meltextruded strand was approximately $1.7 \mathrm{~mm}$. The obtained melt-extruded strand was repeatedly meltrolled at 155 and $150{ }^{\circ} \mathrm{C}$ in order and with the gap decreased stepwise. The thickness of the obtained tape (as-rolled tape) was approximately $200 \mu \mathrm{m}$. The as-rolled tape was melt-drawn at $155{ }^{\circ} \mathrm{C}$ under different strain rates. The highest maximum $D R$ was observed for the strain rate of $5 / \mathrm{min}$, for which the well-balanced development of chain disentanglement and oriented crystallization occurred during meltdrawing. ECCs were formed by melt-drawing and developed with increasing $D R$, resulting in high tensile strength. The melt-drawn tape prepared by melt-drawing with $D R$ of 15 under a strain rate of 5/ min exhibited the most enhanced ECC formation and the highest $D_{\mathrm{c}}$, and the tensile strength and thickness were $0.56 \mathrm{GPa}$ and $70 \mu \mathrm{m}$, respectively. Consequently, a thin UHMW-PE tape with superior tensile strength was prepared from UHMW-PE reactor powder by multiple melt processing, i.e., melt-extrusion, meltrolling, and melt-drawing.

\section{Acknowledgement}

This work was partly supported by The Ogasawara Foundation for the Promotion of Science \& Engineering.

\section{References}

1. H. Uehara, R. Yoshida, M. Kakiage, T. Yamanobe and T. Komoto, Ind. Eng. Chem. Res., 45, 7801 (2006).

2. H. Uehara, T. Tamura, K. Hashidume, H. Tanaka and T. Yamanobe, J. Mater. Chem. A, 2, 5252 (2014).

3. P. Smith and P. J. Lemstra, J. Mater. Sci., 15, 505 (1980).

4. P. Smith and P. J. Lemstra, Polymer, 21, 1341 (1980).

5. P. J. Barham and A. Keller, J. Mater. Sci., 20, 2281 (1985).

6. Z. Bashir and A. Keller, Colloid Polym. Sci., 267, 116 (1989).

7. H. Uehara, M. Nakae, T. Kanamoto, A. E. Zachariades and R. S. Porter, Macromolecules, 32, 2761 (1999).

8. M. Nakae, H. Uehara, T. Kanamoto, T. Ohama and R. S. Porter, J. Polym. Sci., Part B: Polym. Phys., 37, 1921 (1999).

9. M. Nakae, H. Uehara, T. Kanamoto, A. E. Zachariades and R. S. Porter, Macromolecules, 33, 2632 (2000).

10. M. Syouji, D. Sawai, T. Kanamoto and T. Ohama, Sen’i Gakkaishi, 60, 316 (2004).

11. H. Uehara, M. Kakiage, T. Yamanobe, T. Komoto and S. Murakami, Macromol. Rapid Commun., 27, 966 (2006).

12. M. Kakiage, T. Yamanobe, T. Komoto, S. Murakami and H. Uehara, J. Polym. Sci., Part B: Polym. Phys., 44, 2455 (2006).

13. M. Kakiage, T. Yamanobe, T. Komoto, S. Murakami and H. Uehara, Polymer, 47, 8053 (2006).

14. M. Kakiage, M. Sekiya, T. Yamanobe, T. Komoto, S. Sasaki, S. Murakami and H. Uehara, Polymer, 48, 7385 (2007).

15. T. Morioka, M. Kakiage, T. Yamanobe, T. Komoto, Y. Higuchi, H. Kamiya, K. Arai, S. Murakami and H. Uehara, Macromolecules, 40, 9413 (2007).

16. M. Kakiage, M. Sekiya, T. Yamanobe, T. Komoto, S. Sasaki, S. Murakami and H. Uehara, J. Phys. Chem. B, 112, 5311 (2008).

17. M. Kakiage, T. Yamanobe and H. Uehara, Macromol. Rapid Commun., 29, 1571 (2008).

18. M. Kakiage, T. Tamura, S. Murakami, H. Takahashi, T. Yamanobe and H. Uehara, J. Mater. Sci., 45, 2574 (2010).

19. H. Uehara, T. Tamura, M. Kakiage and T. Yamanobe, Adv. Funct. Mater, 22, 2048 (2012).

20. H. Uehara, Y. Arase, K. Suzuki, Y. Yukawa, Y. Higuchi, Y. Matsuoka and T. Yamanobe, Macromol. Mater. Eng., 299, 669 (2014).

21. S. Kato, H. Tanaka, T. Yamanobe and H. Uehara, J. Phys. Chem. B, 119, 5062 (2015).

22. H. Uehara, T. Tamura, H. Yamashita, T. 
Yamanobe and H. Masunaga, J. Phys. Chem. B, 119 , 15909 (2015).

23. M. Kakiage and D. Fukagawa, Mater. Today Commun., 23, 100864 (2020).

24. C. W. M. Bastiaansen, H. E. H. Meyer and P. J. Lemstra, Polymer, 31, 1435 (1990).

25. H. Uehara, T. Obana, M. Kakiage, H. Tanaka, H. Masunaga, T. Yamanobe and E. Akiyama, J. Mater. Chem. C, 2, 373 (2014).

26. L.-H. Wang and R. S. Porter, J. Appl. Polym. Sci., 43, 1559 (1991).

27. Y. L. Joo, H. Zhou, S.-G. Lee, H.-K. Lee and J. K. Song, J. Appl. Polym. Sci., 98, 718 (2005).
28. H. Uehara, T. Hirao, T. Yamanobe, T. Komoto and Y. Yamamoto, Polymer, 47, 7145 (2006).

29. J. Wang and Z. Du, T. Lian, Polym. Eng. Sci., 58, 2156 (2018).

30. P. Gao, M. K. Cheung and T. Y. Leung, Polymer, 37, 3265 (1996).

31. W. Hoogsteen, G. ten Brinke and A. J. Pennings, Colloid Polym. Sci., 266, 1003 (1988).

32. S. Ratner, A. Weinberg, E. Wachtel, P. M. Moret and G. Marom, Macromol. Rapid Commun., 25, 1150 (2004).

33. S. Wu. J. Polym. Sci., Part B: Polym. Phys., 27, 723 (1989). 